\title{
Study on Factors Influencing of College Sci-tech Achievement Transformation Resistance-Based on the Perspective of Researchers' Perceived Risk
}

\author{
Yifan Jin \\ College of Management \\ Wuhan University of Science and Technology \\ Hubei, China \\ 1085307725@qq.com
}

\author{
Tao Chen \\ College of Management \\ Wuhan University of Science and Technology \\ Hubei, China \\ 2763065171@qq.com
}

\begin{abstract}
The present study was designed to study the barriers and the successful model of sci-tech achievement transformation. Our objective in this paper is to analysis the cause of the failure of sci-tech achievement transformation, and then to improve college sci-tech achievement transformation rate. Colleges serve as the source of sci-tech achievement transformation, and their subjective will is a decisive factor influencing the quality and effect of sci-tech achievement transformation. This paper takes analysis of college researchers' perceived risk as the entry point, combines innovation resistance theory, reviews the existing literatures and systematically organizes perceived risk factors influencing college sci-tech achievement transformation, i.e. financial risk, time risk, psychological risk and intellectual property risk, and via the theory to verify that these factors have a positive influence on college researchers' resist transformation. In the end, several countermeasures and suggestions are proposed for sci-tech achievement transformation.
\end{abstract}

Keywords-college sci-tech achievement; perceived risk; innovation resistance; transformation resistance.

\section{INTRODUCTION}

Colleges own abundant reserve of talents, scientific research bases and cultural accumulation, so they become the important birth land of scientific and technological innovation. According to the data provided by Ministry of Science and Technology, 5100 colleges and scientific research universities accomplish 30000 scientific research achievements annually. However, only about $20 \%$ of them can be transformed and produced in quantity, and only $5 \%$ can form industry scale. Low college sci-tech achievement transformation rate has been a problem discussed by numerous scholars. During sci-tech achievement transformation, transformation will and transformation behavior of college scientific researchers as the source of sci-tech achievement transformation are directly related to the result of sci-tech achievement transformation. The study on the failure causes of sci-tech achievement transformation from the college perspective has great theoretical significance and practical significance. This paper will introduce the concept of consumer behavior and start from researchers' perceived risk to study the failure causes of sci-tech achievement transformation.

\section{CONNOTATION OF SCI-TECH ACHIEVEMENT TRANSFORMATION RESISTANCE}

The formal definition of innovation resistance was proposed by Ram in 1985. In his opinion, consumers habitually resist innovative products at first, and later they will take active part in resistance. The process of such persistent behavior is innovation resistance. Later, this definition was modified as follows: innovation resistance refers to consumers' instinctive response to the changes brought by innovative products. Besides, innovation resistance is not equal to consumers' complete refusal of innovative products. The resistance degree will differ and there are mainly three types: delay application, refuse application and oppose application [1].

Innovation diffusion and sci-tech achievement transformation have the common point in essence. The core idea of the former is innovation communication and application, while the core of the latter is diffusion and application of technological innovation. Based on this same point, the research on achievement transformation by combining innovation diffusion theory is a new perspective. It is believed that the process of sci-tech achievement transformation and application is also the process of innovation result discussion in reality. The failure of sci-tech achievement transformation is exactly the failure of innovation diffusion, so innovation resistance theory may be combined to study it. $\mathrm{Li}$ Ying and Chen Tao (2016) associated innovation diffusion with sci-tech achievement transformation and gained the influence of policy orientation on sci-tech achievement transformation resistance, i.e. academic orientation, insufficient motivation and insufficient mandatory protection [2].

Many obstacles exist in the process of sci-tech achievement transformation. Niu Chonghuai et al. considered that the obstacles of sci-tech achievement transformation mainly include system obstacle, input obstacle and market obstacle [3] Shi Guodong indicated that college sci-tech achievement transformation has the following internal obstacles: low practical value of sci-tech achievements, lack of horizontal cooperation between colleges and production enterprises, lack of achievement transformation service system and failure of scientific research incentive and constraint mechanism etc [4]. Internal and external obstacles intensify the risks of sci-tech 
achievement transformation. Colleges as the creators and suppliers of sci-tech achievements perceive huge risks due to the existence of sci-tech achievement transformation obstacles. They do not concern sci-tech achievement transformation or they are unwilling to further transform sci-tech achievements, so innovation resistance forms.

\section{PERCEIVED RISK AND ITS Dimension}

From the psychological perspective, Bauer believed that consumers cannot definitely know whether their expected results are correct in any purchasing behavior, while some results may make consumers unhappy. In the view of Bettman, perceived risk is actually a kind of uncertain feeling in product purchasing process, because consumers cannot predict the buying result and the consequences. Perceived risk consists of two factors: uncertainty about buying result; uncertainty about buying failure consequence. Sheth (1981) proposed that perceived risk is the major factor influencing innovation resistance, and that when innovation belongs to non-continuous diffusion, the innovation resistance degree will be stronger. When consumers perceive more risks, the innovation time is later until they grasp more information through information search. Ram also clearly indicated that risk perception is one of main factors influencing innovation resistance.

Many researches show perceived risks is a multidimensional concept. Based on summarizing predecessors' researches, Stone and Gronhaug reduced total perceived risks to functional risk, physical risk, financial risk, psychological risk, social risk and time risk, and proved that the 6 dimensions could explain nearly $88.8 \%$ of total perceived risks [5]. Subsequent scholars referred to the 6 dimensions to study product categories. Jing Sen, Zhou Ying and Peng Juan (2005) proposed that different products should be combined in the research on perceived risk and consumers have different perceived risk for different products. In this paper, qualitative research method is applied to deeply interview college teachers, and relevant documents are sorted to gain the conclusion that sci-tech achievement transformation is different from purchasing practical products, and functional risk and physical risk do not exist. Since college teachers own strong degree of education and psychological quality, and the surroundings also encourage sci-tech achievement transformation, social risk is not obvious. Achievement transformation is actually technological transfer, and involves complex process and many subjects. There is intellectual property dispute or technological loss. Thus, intellectual property risk exists. In conclusion, this paper divides the dimensions of perceived risk influencing sci-tech achievement transformation into financial risk, time risk, psychological risk and intellectual property risk.

\section{Research About Influence of Perceived Risk on COLLEGE SCI-TECH ACHIEVEMENT TRANSFORMATION RESISTANCE}

\section{A. Influence of Financial Risk on College Sci-Tech Achievement Transformation Resistance}

The process of sci-tech achievement transformation is a transaction process, and high expense cost is needed. The cost is financial risk of sci-tech achievement transformation. Liu Zhiyuan et al. (2003) mentioned that unusual high transaction barrier and transaction cost exist between transformation parties when analyzing obstructive factors and difficulties of college patented technology achievement industrialization [6]. Jerry (2003) considered that high cost and high risk are two significant features of industry-university-research cooperative innovation, and cost reduction contributes to achieving benefit maximization of both parties [7]. Shao Jingfeng et al. (2013) also thought that for each subject of industry-universityresearch, cost reduction can improve transformation power [8]. Li Ying and Chen Tao (2016) constructed structural equation model to study the influence of transaction cost on transformation resistance. The result shows that transaction cost presents weak positive effect on transformation resistance, and significant positive effect on transformation delay [9].

The development of sci-tech achievement application requires strong fund support, strict market test and problem solving capacity. Hence, scientific researchers need to spend painstaking efforts, including manpower, materials and financial resources etc. Thus, cost risk exists in sci-tech achievement transformation, which influences sci-tech achievement resistance.

\section{B. Influence of Time Risk on College Sci-Tech Achievement Transformation Resistance}

Sci-tech achievement transformation is a long-term and high-risk systematical project. From functional perspective, sci-tech achievement transformation process can be divided into three links: laboratory stage, productization stage and commercialization or industrialization stage. Each link will consume researchers' plentiful energy and time. At present, colleges regard the number of papers published, the number of monographs published, prize grade and the number of prizes as the evaluation indexes. Sci-tech achievement transformation is not the main work of college teachers, and the time they are willing to spend on achievement transformation is very limited. Researches show that $46.5 \%$ of people will choose cooperation with external enterprises in transformation and operation. Meanwhile, many choose patent transfer or authorization. The proportion of people selecting independent operation is minimum (8.1\%). This embodies the respondents are unwilling to spend too much time and energy on achievement transformation. Effective reduction of the time spent by scientific researchers on achievement transformation can better facilitate achievement transformation. Shao Jingfeng (2013) held that for each subject of industry-university-research, cost reduction can improve transformation power.

\section{Influence of Psychological Risk on College Sci-Tech Achievement Transformation Resistance}

Psychological risk refers to consumers' expected anxiety, uneasiness and repentant feeling after making wrong purchase or use behavior. In this paper, psychological risk refers to researchers' negative emotion caused by the worry about transformation failure. Guo Qiang (2012) explicitly indicated that sci-tech achievement transformation is faced with various risks such as technological risk, market risk and intellectual property risk. Because scientific researchers fear continuous cooperation achievement cannot be usefully transformed, or lose the competitive edge in the process and suffer the unfair treatment, their transformation will is weak [10]. 


\section{Influence of Intellectual Property Risk on College Sci-Tech Achievement Transformation Resistance}

The process of transforming sci-tech achievements into practical productivity is the process of transforming "intangible assets" into "tangible assets". This process involves intellectual property problem. There are two types of risks. The first one is infringement risk, i.e. intellectual property problem of non-risk enterprise party caused by information asymmetry in achievement transformation process. The second one is secret disclosure risk. It results from disclosure of technological secret by risk enterprise party in achievement transformation process. Szulanski's researches indicate that when knowledge owner lacks incentive or inducement, he may not actively share knowledge for fear of losing knowledge ownership as well as dominant and privileged position. Intellectual property right protection system is not mature in China. A series of legal risks such as intellectual property dispute and the loss of income still exist in college sci-tech achievement transformation. These risks further affect college sci-tech achievement transformation and restrict researchers' transformation enthusiasm.

Moreover, colleges also fall behind in terms of intellectual property management mechanism. For example, there is short of professional intellectual property management institution and professional personnel; the contract and agreement are not standard; intellectual property articles are not clear. According to the interview contents, it is known that many teachers once experienced intellectual property disputes so that they feared achievement transformation. It is hard to guarantee transformation benefit and safeguard legal rights. These problems intensity transformation risks and greatly weaken transformation enthusiasm of college researchers.

\section{Suggestions ON SCI-TECH ACHIEVEMENT TRANSFORMATION}

\section{A. To Introduce Sci-Tech Achievement Transformation Evaluation and Examination System}

Evaluation and examination system is the baton of scientific and technical personnel in scientific research work. Colleges should actively explore reform of scientific research personnel management system, encourage the research team with sci-tech achievements to participate in sci-tech achievement promotion work, and study the reform of sci-tech achievement transformation system according to features of sci-tech achievement transformation. In the aspect of teacher evaluation and examination, sci-tech achievement transfer and transformation should be brought into job title evaluation and post promotion, and the evaluation should be carried out in accordance with sci-tech achievement transformation performance. In terms of motivation, it is necessary to mobilize enthusiasm of scientific researchers, formulate sci-tech achievement transfer and transformation income distribution and stock ownership incentive scheme as per national laws and regulations and guarantee the income of scientific researchers.

\section{B. To Establish Relevant System Matched With Sci-Tech Achievement Transfer and Transformation}

Colleges should establish and improve relevant rules and management systems to facilitate sci-tech achievement transformation in accordance with the newly modified Law of the PRC on Promoting the Transformation of Scientific and Technological Achievements, improve service function of college sci-tech achievement transformation, guarantee legal interest of each party in sci-tech achievement transformation, enhance intellectual property protection, fully mobilize enthusiasm and creativity of college scientific researchers and promote sci-tech achievement innovation and sci-tech achievement transformation. To be specific, colleges should transfer sci-tech achievement disposition right, specify achievement ownership, increase the income of inventors, reform sci-tech achievement transformation mechanism, innovate for sci-tech achievement transformation evaluation mechanism, improve matched services for sci-tech achievement transformation and guide capital to facilitate sci-tech achievement transformation.

\section{To Build Professional Sci-Tech Achievement Transformation Team and College Intermediary Service Institution}

Building professional sci-tech achievement transformation team can effectively help scientific researchers transform sci-tech achievements, reduce manpower and material expenditure, strengthen intellectual property protection awareness and enhance the enthusiasm of college scientific researchers for sci-tech achievement transformation. Depending on the intermediary service institution established by colleges is an important way for colleges to give play to resource advantage, achieve technology transformation and reflect social service function. Besides, it is also a significant approach to effectively transfer transformation risk of scientific researchers and boost sci-tech achievement transformation efficiency.

\section{CONCLUSIONS}

College sci-tech achievement transformation has been an important topic for college development and technological innovation field. It has been valued by colleges and governmental competent department for many years. Exploring the failure reasons for college sci-tech achievement transformation by combining innovation resistance and perceived risk theory contributes to studying sci-tech achievement transformation from a new perspective. This paper analyzes the influence of perceived risk on college sci-tech achievement transformation resistance only from qualitative aspect. In future, other factors influencing college sci-tech achievement transformation resistance may be further explored, and relevant empirical analysis may be implemented to provide theoretical support for sci-tech achievement transformation and strive to bring some breakthroughs for college sci-tech achievement transformation.

\section{REFERENCES}

[1] Ram S. A model of innovation resistance [J]. Advances in Consumer Research, 1987,14(1): 208-212.

[2] Chen Tao, Li Ying, Study about Influence of Policy Orientation on College Sci-tech Achievement Transformation Resistance [J]. Sciencepaper Online, 2016. (In Chinese)

[3] Niu Chonghuai, Liu Tao, Wang Yan, Analysis of Sci-tech Achievement Transformation Obstacles [J]. China Business Economic Theory Research, 2009(12): 29-30. (In Chinese) 
[4] Shi Guodong, Internal Obstacles of Sci-tech Achievement Transformation and Countermeasures [J]. Education and Vocation, 2012 (14): 171-173. (In Chinese)

[5] Li Baoling, Li Qi, Analysis on Consumers’ Perceived Risk in Internet Shopping: Its Components and Sources [J]. Economic Management, 2007(2): 78-83. (In Chinese)

[6] Liu Zhiyuan, Tan Shuqin, Crossing the Wide Gap between Patent Achievements and Commercial Value - empirical study on Sci-tech Achievement Transformation [J]. Science \& Technology Progress and Policy, 2003,20(2):101-103. (In Chinese)

[7] Richard A,Jensen,Jerry G,et al. Disclosure and licensing of University inventions: The best we can do with the S\&T we get to work with [J].International Journal of Industrial Organization,2003,21(9):
1271-1300.

[8] Shao Jingfeng, Wang Jinfu, Ma Xiaohong et al., Optimization of Key Dynamic of Industry-University-Research Collaborative Innovation Based on the Data [J]. Chinese Journal of Management Science, 2013(S2):731-735. (In Chinese)

[9] Li Ying, Chen Tao, Research on College Sci-tech Achievement Transformation obstacles and Policy - Based on the Perspective of Innovation Resistance [D]. Wuhan University of Science and Technology, 2016. (In Chinese)

[10] Guo Qiang, Xia Xiangyang, Zhao Li, Study on Factors Influencing College Sci-tech Achievement Transformation and Countermeasures [J]. Science \& Technology Progress and Policy, 2012, 29(6):151-153. (In Chinese) 